Artigo Original

\title{
DETERMINAÇÃO DE pH IDEAL PARA AUMENTO DE PRODUTIVIDADE NO PROCESSO DE BIOTRANSFORMAÇÃO DE ESTEROIDES
}

\author{
Autores: Cleiton Oliveira Leite'; Jailson Cardoso dos Santos'; \\ Dalton Giovanni Nogueira da Silva ${ }^{2, A}$ \\ 1Discentes do Curso de Farmácia, Faculdade Estácio de Carapicuíba, São Paulo, Brasil. \\ ${ }^{2}$ Professor da Faculdade Estácio de Carapicuíba, São Paulo, Brasil.
}

\section{Informações do artigo}

Palavras Chave:

Fermentação,

biotransformação, $\mathrm{pH}$.

\section{Resumo}

O desenvolvimento dos esteroides é um dos mais fascinantes campos da medicina, química e microbiologia industrial, principalmente devido ao fato de vários esteroides discrepantes, como os ácidos biliares e os hormônios sexuais, dentre outros, serem essenciais para os processos biológicos. O termo de biotransformação ocorre devido ao processo em que substâncias como o fármaco, nutrientes, dejetos e toxinas dentro de um organismo passam por reações químicas, sendo geralmente medidas por enzimas, que as transforma em um composto contrário do insólito administrado. Para o tratamento de algumas doenças foi necessária a administração de esteroides ou hormônios, mas, devido a sua complexidade, a obtenção da forma sintética dessas moléculas é proibitivamente cara. Desencadearam-se então experimentos com biotransformação; isso pode ocorrer com a presença do microrganismo ou pode-se produzir a enzima através do crescimento do microrganismo e posterior extração. A maior vantagem da biotransformação em relação à síntese química é a seletividade e a economia de processos. Devido a gama de opções na biotransformação de esteroides passou-se a ser factível a obtenção de novas moléculas até então não existentes na natureza, o que proporcionou a criação de medicamentos melhores e com menos efeitos colaterais. Estudos feitos com uma cepa do fungo Curvularia lunata mostraram que o controle de $\mathrm{pH}$ é necessário para manter a enzima no melhor nível de produção, e que o máximo de crescimento do microrganismo foi atingido quando o $\mathrm{pH}$ foi controlado em 7,0. Posto isto, os resultados descobertos entre as condições experimentais foram paragonados as porcentagens do esteroide formado contra a porcentagem de esteroide de partida, $\mathrm{pH}$, crescimento e esterilidade.

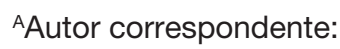

Dalton Giovanni Nogueira da Silva - E-mail: dalton@dalton.pro.br - ORCID: https://orcid.org/0000-0001-7607-1612

DOI: https://doi.org/10.31415/bjns.v3i1.79 - Artigo recebido em: 21 de outubro de 2019 ; aceito em 10 de fevereiro de 2020 ; publicado em 10 de março de 2020. Brazilian Journal of Natural Sciences, Vol. 3, N.1, março 2020. Disponível online a partir de 10 de março de 2020, ISSN 2595-0584. www.bjns.com.br. Todos os autores contribuíram igualmente com o artigo. Os autores declaram não haver conflito de interesse. Este é um artigo de acesso aberto sob a licença CC - BY: http://creativecommons.org/licenses/by/4.0 


\section{Article ID}

Keywords:

Fermentation, bio-transformation, $\mathrm{pH}$.

\begin{abstract}
The development of steroids is one of the most fascinating fields of medicine, chemistry and industrial microbiology, mainly due to the fact that many discrepant steroids, such as bile acids and sex hormones, among others, are essential for biological processes. The term biotransformation occurs due to the process in which substances such as the drug, nutrients, waste and toxins within an organism undergo chemical reactions, being generally measured by enzymes, which turns it into an opposite compound of the unusual administered. For the treatment of some diseases the administration of steroids or hormones has been necessary but due to their complexity, obtaining the synthetic form of these molecules is prohibitively expensive. Experiments with bio-transformation began; This may occur with the presence of the microorganism or the enzyme may be produced by microorganism growth and subsequent extraction. The biggest advantage of bio-transformation over chemical synthesis is selectivity and process economics. Due to the wide range of options in steroid bio-transformation, it was now feasible to obtain new molecules not previously found in nature, which led to the creation of better drugs with less side effects. Studies with a strain of the fungus Curvularia lunata showed that $\mathrm{pH}$ control is necessary to keep the enzyme at the best production level, and that the maximum growth of the microorganism was reached when the $\mathrm{pH}$ was controlled at 7.0. That said, the results found between the experimental conditions were compared to the percentages of the steroid formed against the percentage of starting steroid, $\mathrm{pH}$, growth and sterility.
\end{abstract}

\section{Introdução}

A história do desenvolvimento dos esteroides é uma das mais fascinantes e destacadas no campo da medicina, química e microbiologia industrial. Principalmente devido ao fato de que vários esteroides diferentes, como os ácidos biliares, os hormônios sexuais, dentre outros, serem essenciais para os processos biológicos. Os sistemas biológicos obedecem às leis da química, sendo que o termo de biotransformação ocorre devido às modificações da estrutura química que são realizadas a temperaturas de $20 \mathrm{a} 40^{\circ} \mathrm{C}$, requerendo um significativo aporte energético e que, geralmente são realizadas em meio aquoso. Atualmente os microrganismos são utilizados como reativos químicos para a preparação de intermediários, ou para a produção econômica de produtos. Para o tratamento de algumas doenças era necessária a administração de esteroides ou hormônios e devido a sua complexidade, a obtenção de forma sintética dessas moléculas é proibitivamente cara. Iniciaram-se então experimentos com biotransformações, ou seja, transformação com auxílio de um sistema enzimático gerado por microrganismos. Isso pode ocorrer com a presença do microrganismo ou pode-se produzir a enzima através do crescimento do microrganismo e posterior extração (CASTRO, H. F. et al., 2004).

A biotransformação é um processo biológico pelo qual um composto orgânico é modificado para um produto recuperável, mediante reações simples, quimicamente definidas, catalisadas por enzimas celulares. As biotransformações diferem das fermentações, nas quais os produtos, como antibióticos, enzimas, aminoácidos, ácidos orgânicos e solventes originam-se a partir de um complexo sistema Biosintética do metabolismo primário ou secundário. Outras transformações utilizadas atualmente em escala industrial, tem utilizado diferentes microrganismos (ANDRADE, J. S., PANTOJA, L., MAEDA, R. N., 2003).

A fermentação ou biotransformação, microrganismos podem ser usados para converter compostos a partir de outras estruturas para produtos de maior valor agregado. As células microbianas comportam-se como catalisadores quirais com grande especificidade 
posicional e estereospecificidade. Assim, processos microbiológicos são mais específicos que processos químicos, promovendo modificações ou removendo grupos funcionais em locais específicos numa molécula complexa. As reações catalisadoras incluem desidrogenação, oxidação, hidroxilação, desidratação e condensação, descarboxilação, aminação, deaminação e isomerização. Os processos microbianos têm ainda a vantagem sobre os processos químicos de operação em baixas temperaturas e pressões, (BASTOS, REINALDO GASPAR, EDUFSCAR, 2010).

A maior vantagem da biotransformação em relação à síntese química é a seletividade e a economia de etapas. O que é feito facilmente com a biotransformação podem necessitar de mais de 30 reações químicas fazendo com que a viabilidade econômica não exista. Existe praticamente para cada reação orgânica um processo enzimático equivalente que tem como vantagens a quimiosseletividade, a regiosseletividade, a diastereosseletividade e a enantiosseletividade, (FABER, 1997).

Devido a gama de opções na biotransformação de esteroides passou-se a ser factível a obtenção de novas moléculas até então não existentes na natureza, o que proporcionou a criação de medicamentos melhores e com menores efeitos colaterais. Estudos feitos com uma cepa do fungo Curvularia lunata mostrou que o controle de $\mathrm{pH}$ é necessário para manter a enzima no melhor nível de produção, e que o máximo de crescimento do microrganismo foi atingido quando o $\mathrm{pH}$ foi controlado em 7,0 (BANERJEE \& SRIVASTAVA, 1992).

A hidroxilação é realizada pelas enzimas hidroxilases; no caso do fungo Rhizopus arrhizus a enzima é a $11 \alpha$-hidroxilase, esse nome é dado devido ao fato da hidroxila ser colocada na posição 11 do esqueleto esteroidal e com a configuração espacial aa-hidroxilase, conforme mostrado na figura 1.1.

Figura 1.1 - Hidroxilação realizada através de biotransformação.
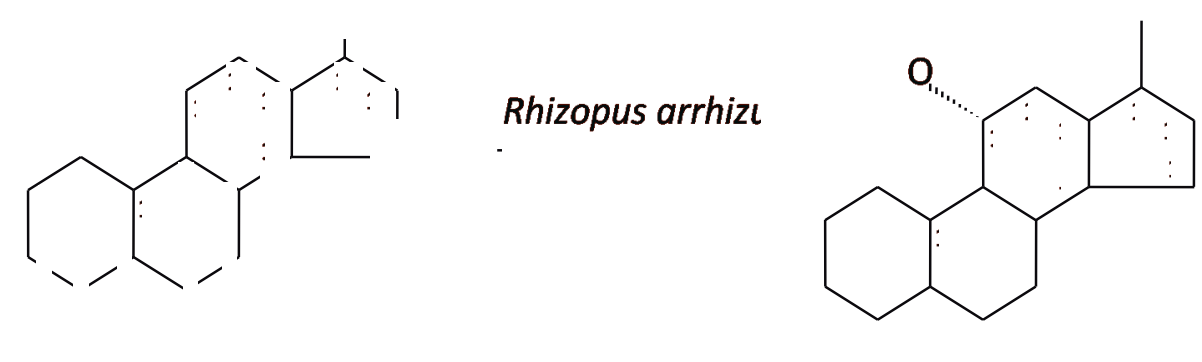

Fonte: Autores

\section{Material e Método}

\section{Preparação do meio de cultura:}

Para realização do estudo, foi preparado meio de cultura, iniciando pela pesagem das matérias primas (meio de cultivo), pesando-se, em balança analítica, $0,600 \mathrm{~kg}$ de Dextrose, $0,150 \mathrm{~kg}$ de Peptona e $0,003 \mathrm{~kg}$ de Silicone, os matérias foram transferidos para um béquer de 2 litros contendo, 1 litros de água destilada, agitou-se a 100 rpm, com auxílio de agitação magnética, até dissolução das matérias primas. Após a completa dissolução o volume foi avolumado para 1,5 L com água destilada e aliquotado para 14 Erlenmeyer de $500 \mathrm{~mL}$, sendo transferido $100 \mathrm{~mL}$ do meio de cultivo para cada Erlenmeyer. Posteriormente distribui- ção do meio, os frascos foram numerados de 1 a 14 .

Como o objetivo era avaliar o efeito do $\mathrm{pH}$, tivemos de garantir que os frascos tivessem o seu $\mathrm{pH}$ controlado durante o experimento fermentativo, para isso foi efetuado, com a adição de soluções tampões $4,00,7,00$ e 9,00 nos frascos onde o pH necessitava ser controlado e nos frascos onde o $\mathrm{pH}$ deveria ser livre adicionou-se a mesma quantidade de água destilada para equivalência das concentrações dos nutrientes. Conforme descrito na tabela $\mathbf{1}$, foi adicionado a cada frasco, $10 \mathrm{~mL}$ da solução descrita na coluna 2 .

Após a distribuição das soluções, os frascos foram fechados com tampão de gaze e esterilizados em autoclave a $121^{\circ} \mathrm{C}$ durante 30 minutos. A autoclavagem e aquecimento a $121^{\circ} \mathrm{C}$ durante 30 minutos a 1.02 atm. são processo mais eficaz, pois o seu poder de penetra- 
ção é maior, numa atmosfera húmida e a uma temperatura elevada, os microrganismos morrem quando se dá a coagulação e desnaturação das enzimas e proteínas que fazem parte da sua estrutura. Este processo de eliminação de todos contaminantes é de extrema importância para o processo fermentativo, pois posteriormente realiza-se a inoculação do nosso microrganismo e para obtenção de bons resultados, deve-se ter somente o nosso microrganismo, caso todos os contaminantes não sejam eliminados, estes competiram com o nosso microrganismo Rhizopus arrhizus, desta forma interferindo no crescimento e na produtividade.

Tabela 1 - Distribuição de tampão em cada frasco, correspondendo às diferentes situações de crescimento de Rhizopus arrhizus.

\begin{tabular}{l|l}
\hline Frasco & Solução a ser adicionada \\
\hline 01 & Água destilada \\
\hline 02 & Água destilada \\
\hline 03 & Água destilada \\
\hline 04 & Água destilada \\
\hline 05 & Água destilada \\
\hline 06 & Solução Tampão pH 4,0 \\
\hline 07 & Solução Tampão pH 4,0 \\
\hline 08 & Solução Tampão pH 4,0 \\
\hline 09 & Solução Tampão pH 7,0 \\
\hline 10 & Solução Tampão pH 7,0 \\
\hline 11 & Solução Tampão pH 7,0 \\
\hline 12 & Solução Tampão pH 9,0 \\
\hline 13 & Solução Tampão pH 9,0 \\
\hline 14 & Solução Tampão pH 9,0 \\
\hline
\end{tabular}

Fonte: Autores

\section{Inoculação e crescimento do fungo}

Dois tubos de fungo Rhizopus arrhizus foram inoculados em fluxo laminar, um para o frasco 01 e outro tubo o frasco 02 . Em seguida os tubos foram incubados em Scheker com agitação de $150 \mathrm{rpm}$ e temperatura de $27^{\circ} \mathrm{C}$ por um período de 48 a 72 horas, tempo determinado para a adaptação e crescimento de microrganismo:

A. Crescimento microbiano: É normalmente associado ao crescimento de uma população de células de um dado microrganismo, ou seja, aumento do número de células da população.

B. Incubadora Shaker: É um equipamento de laboratório responsável pela agitação de experimentos em temperatura controlada e proteger essa ação de fatores externos, promovendo assim a incubação, exerce um movimento orbital de forma contínua, pode se ter o efeito de aquecimento ou resfriamento. As substâncias são agitadas sem que haja contato com o ambiente externo. Não havendo interferência de elementos indesejados.

Após crescimento, foram misturados os conteúdos dos frascos 01 e 02 (inóculo), para homogeneizá-los, minimizando diferenças no inóculo dos frascos subsequentes e coletada amostra para realização de análise de esterilidade, $\mathrm{pH}$ e crescimento. Foi transferido $10 \mathrm{~mL}$ do inóculo dos frascos 01 e 02 para cada frasco, de 03 a 14 e posteriormente foram incubados por 24 horas sobre agitação de $150 \mathrm{rpm}$ e temperatura de $27^{\circ}$ $\mathrm{C}$, sendo coletada amostras para análises de esterilidade, crescimento e $\mathrm{pH}$. Após 24 horas de crescimento, foi adicionado 0,05 g/L de esteroide estéril (progesterona) em cada um dos frascos e posteriormente foram incubados por mais 48 horas (tempo de biotransformação) mantendo agitação de $150 \mathrm{rpm}$ e temperatura de $27^{\circ} \mathrm{C}$. Após 48 horas de transformação, os frascos foram retirados da incubadora e efetuado análise de esterilidade, crescimento e $\mathrm{pH}$ de cada frasco e avaliação da biotransformação.

\section{Parâmetros físico e físico-químicos que devem ser considerados no processo de fermentação}

O oxigênio: é um dos substratos gasosos mais importantes para o metabolismo microbiano. Não é um gás muito solúvel em água, sendo que uma solução saturada contém aproximadamente $9 \mathrm{mg} \mathrm{O} 2 / \mathrm{L}\left(25^{\circ} \mathrm{C}\right)$ e devido aos ingredientes do meio de cultivo a saturação é ainda menor. Portanto é necessário injetar ar no meio de cultura, através de aeradores, durante o processo fermentativo. $\mathrm{O}$ ar é injetado na parte inferior geralmente através de difusores para controlar o tamanho das bolhas. Pode-se dissolver centenas de gramas de glicose em água, mas a solubilidade do oxigênio a $1 \mathrm{~atm}$. a $35^{\circ} \mathrm{C}$ é da ordem de $7 \mathrm{mgO} 2 / \mathrm{L}$ ( $\left.7 \mathrm{ppm}\right)$. Desta forma de nada adianta colocar centenas de gramas por litro de glicose do meio de cultivo se não se consegue transferir oxigênio ao microrganismo numa velocidade suficientemente grande para suportar um 
crescimento exclusivamente aeróbio (BERNARDES, T. F., et al., 2008). Temperatura: o controle de temperatura é efetuado através de camisa com circulação de água gelada e água quente, ligado a um termostato de acordo com o comportamento do microrganismo, sendo este um parâmetro muito importante, pois todos os microrganismos possuem uma temperatura ótima para o processo de biotransformação, uma temperatura alta ou baixa, irá alterar o metabolismo do microrganismo impactando assim na síntese do fármaco (VOLPE, P. L. O., 1997).

Esterilização: a esterilização de um meio de cultivo ou ambiente é a operação de eliminação de formas vegetativas e esporuladas de microrganismos. A esterilização difere da desinfecção pelo fato de que neste último processo ocorre o emprego de uma substância que destrói ou inibe o crescimento de certos microrganismos em determinados meios. Os agentes físicos entendem-se calor, filtração e radiação, como agentes químicos temos o emprego de ácidos, bases, sais, halogênios, álcoois, éteres e fenóis. A esterilização pelo calor seco é feita a temperatura de $160-170^{\circ} \mathrm{C}$ por duas horas, não sendo aplicados a meios de cultivos ou líquidos, mas na vidraria, no material de laboratório e no recheio dos filtros de ar. A esterilização com calor úmido é feita num ambiente de vapor saturado a $1 \mathrm{~atm}$. de pressão $\left(\mathrm{T}=121^{\circ} \mathrm{C}\right)$ durante $15-20$ minutos, condições suficientes para eliminação das formas mais resistentes, os esporos de bactérias. (BASTOS, REINALDO GASPAR, EDUFSCAR, 2010).

Agitação: Os processos microbianos conduzidos em aerobiose encontram uma situação de enorme destaque entre os cultivos microbianos de interesse industrial, incluindo a produção de antibióticos, enzimas, vitaminas, biomassa, proteínas recombinantes e tratamento biológico de águas residuárias, em todos esses casos há necessidade de um adequado dimensionamento do sistema de transferência de oxigênio, que compreende a operação de dissolução do oxigênio contido na fase gasosa para a fase liquida, em que ocorre o consumo pelos microrganismos. (BASTOS, REINALDO GASPAR, EDUFSCAR, 2010).

$\mathbf{O} \mathbf{p H}$ : influencia a atividade enzimática interferindo na estabilidade dos grupos ionizáveis das enzimas, no sítio ativo e na conformação tridimensional das moléculas, $\mathrm{O} \mathrm{pH}$ adequada propicia que os grupamentos do sítio ativo fiquem na forma química adequada para interagirem com o substrato. Em geral, a enzimas são ativas numa faixa limitada de $\mathrm{pH}$ e em muitos casos existe um valor ótimo, (BASTOS, REINALDO GASPAR, EDUFSCAR, 2010).

O controle de pressão: está relacionado a uma das condições ideais de biotransformação do microrganismo. Caso exista uma pressão extrema dentro dos biorreatores, o microrganismo poderá ser afetado, não evoluindo de forma esperada para a produção do produto desejável.

Feed: Fonte de nutrientes, para manter a constância do crescimento do microrganismo, é possível identificar quando será necessário ser realizado esta adição, acompanhando os parâmetros acima, onde regras de monitoramento, tanto de $\mathrm{pH}$, temperatura, vazão e aeração são fundamentais e indispensáveis para que se tenha o máximo de aproveitamento enzimático para alcançar o produto desejado (RODRIGUES, P. H. M., et al., 2004).

\section{Análise de esterilidade, pH e PCV (volume de células compactadas)}

Para confirmação da esterilidade, $\mathrm{pH}$ e PCV, foram realizadas a seguintes análises:

TSB: Tubos de caldo de soja tripticaseína, $9 \mathrm{~mL}$ de TSB mais 1 loop da amostra: transferência de alíquota da amostra em tubo de ensaio de maneira asséptica e incubação em estufa a uma temperatura entra 34,5 a $39,5^{\circ} \mathrm{C}$, por 24 horas.

TSA: Estrias no meio em placa: semeadura da amostra em placa de petri de maneira asséptica e incubação em estufa a uma temperatura entre 34,5 a $39,5^{\circ} \mathrm{C}$, por 48 horas.

MEA: Estrias no meio em placa: semeadura da amostra em placa de petri de maneira asséptica e incubação em estufa a uma temperatura entre 23 a $26^{\circ} \mathrm{C}$, por 120 horas. Durante os experimentos realizados não foi evidenciado nenhum tipo de contaminação (ausência de microrganismo estranho).

PCV: transferência de $10 \mathrm{~mL}$ da amostra em tubo e centrifugação por 10 minutos a $900 \mathrm{rpm}$. Ao final da centrifugação avaliar o volume depositado no fundo e tubo, usando a escala de volumétrica do tubo, multiplicar o volume por 10 .

Ex.: sólido depositado igual a 15 X $10=$ a $15 \%$ de PVC.

Nos experimentos realizados obteve-se todos os crescimentos acima da especificação de $20 \%$ para o microrganismo de interesse, os resultados obtidos encontram-se na tabela 03 . 
pH: inserir o eletrodo do pHmetro, devidamente calibrado, no frasco contendo a amostra, e registro do valor apresentado no visor do aparelho, assim que este valor se mostrar estável. os resultados obtidos encontram-se na tabela 03.

\section{Análise da Biotransformação}

Para avaliar o rendimento da biotransformação, foram transferidos $10,0 \mathrm{~g}$ do caldo fermentado de cada um dos frascos para béquer de $50 \mathrm{~mL}$, posteriormente foram adicionados $10,0 \mathrm{~g}$ de metanol e cada um dos béqueres, em seguida agitou cada frasco por $10 \mathrm{minu}-$ tos, após agitação, os conteúdos dos béqueres, foram filtrados em papel de filtro qualitativo. Após filtração as amostras foram analisadas para quantificação da biotransformação em HPLC (Cromatografia Líquido de Alta Performance) Agilent, conforme método descritas abaixo:

Utilizou-se uma coluna de aço inox $(250,0 \mathrm{~mm}$ $\mathrm{x}$ 4,6 mm) C-18 fase reversa e 5,0 $\mathrm{mm}$ tamanho de partícula, com a coluna a temperatura ambiente, a fase móvel utilizada foi acetonitrila/água (60:40), com um fluxo da fase móvel de 1,0 ml min-1, o volume injetado foi de 2 microlitros, o detector utilizado foi VWD (comprimento de onda variável), com um comprimento de ondas de $242 \mathrm{~nm}$.

Utilizou-se a cromatografia líquida de alta eficiência (CLAE; em inglês: High performance liquid chromatography, HPLC) por ser um método de separação de compostos químicos em solução, a qual é utilizada na química analítica para identificar e quantificar cada componente em uma mistura, por ter boa sensibilidade, na separação de compostos não voláteis e termicamente estáveis.

\section{RESULTADOS}

Os resultados analíticos encontrados foram avaliados entre as condições do experimento. Foram comparadas as porcentagens do esteroide formado contra a porcentagem de esteroide de partida, $\mathrm{pH}$, crescimento e esterilidade. Através da análise dos resultados analíticos nos cromatogramas, verificando-se os perfis cromatográficos avaliou-se o impacto da variação do $\mathrm{pH}$ para a biotransformação bem como para o crescimento do microrganismo. As cópias dos cromatogramas das respectivas análises encontram-se em anexo.

Na tabela 2 encontramos os valores de porcentagem do esteroide formado e do esteroide de partida, e na tabela 3 são apresentados os dados de crescimento, $\mathrm{pH}$ e esterilidade antes e após a biotransformação.

Podemos observar que os frascos sem controle de $\mathrm{pH}$ através de tamponamento do meio tiveram uma maior variação no $\mathrm{pH}$ após a biotransformação do que nos frascos tamponados. Observamos também que os maiores crescimentos foram encontrados nos frascos com pH livre e pH controlado em 7,0 assim como os melhores resultados de biotransformação.

Tabela 2 - Análise do esteroide de partida e formado por HPLC

\begin{tabular}{|c|c|c|c|c|c|c|c|}
\hline \multirow{2}{*}{ Frasco } & \multirow{2}{*}{ Condição de pH } & \multicolumn{3}{|c|}{$\%$ Esteroide formado } & \multicolumn{3}{|c|}{$\%$ Esteroide de partida } \\
\hline & & Individual & Média & Erro & Individual & Média & Erro \\
\hline 03 & \multirow{3}{*}{ Livre } & 97,55 & \multirow{3}{*}{97,54} & \multirow{3}{*}{0,01} & 0,98 & \multirow{3}{*}{0,99} & \multirow{3}{*}{0,01} \\
\hline 04 & & 97,53 & & & 1,00 & & \\
\hline 05 & & 97,53 & & & 0,99 & & \\
\hline 06 & \multirow{3}{*}{4} & 68,04 & \multirow{3}{*}{68,03} & \multirow{3}{*}{0,01} & 30,92 & \multirow{3}{*}{30,92} & \multirow{3}{*}{0,02} \\
\hline 07 & & 68,02 & & & 30,94 & & \\
\hline 08 & & 68,04 & & & 30,91 & & \\
\hline 09 & \multirow{3}{*}{7} & 98,51 & \multirow{3}{*}{98,51} & \multirow{3}{*}{0,01} & 0,00 & \multirow{3}{*}{0,00} & \multirow{3}{*}{0,00} \\
\hline 10 & & 98,51 & & & 0,00 & & \\
\hline 11 & & 98,52 & & & 0,00 & & \\
\hline 12 & \multirow{3}{*}{9} & 19,47 & \multirow{3}{*}{19,68} & \multirow{3}{*}{0,22} & 80,43 & \multirow{3}{*}{80,22} & \multirow{3}{*}{0,22} \\
\hline 13 & & 19,90 & & & 80,00 & & \\
\hline 14 & & 19,68 & & & 80,22 & & \\
\hline
\end{tabular}

Fonte: Autores 
Tabela 3 - Dados de crescimento, pH e esterilidade antes da Biotransformação

\begin{tabular}{|c|c|c|c|c|c|c|c|}
\hline \multirow[t]{3}{*}{ Frasco } & \multirow[t]{3}{*}{ Condição de pH } & \multicolumn{6}{|c|}{ Antes da Biotransformação } \\
\hline & & \multicolumn{3}{|c|}{ pH } & \multicolumn{3}{|c|}{ \% Crescimento } \\
\hline & & Individual & Média & Erro & Individual & Média & Erro \\
\hline 01 e 02 & Inóculo & 6,8 & - & - & 30 & - & - \\
\hline 03 & \multirow{3}{*}{ livre } & 6,7 & \multirow{3}{*}{6,7} & \multirow{3}{*}{0,1} & 28 & \multirow{3}{*}{28,7} & \multirow{3}{*}{0,6} \\
\hline 04 & & 6,6 & & & 29 & & \\
\hline 05 & & 6,7 & & & 29 & & \\
\hline 06 & \multirow{3}{*}{4} & 4,0 & \multirow{3}{*}{4,0} & \multirow{3}{*}{0,1} & 25 & \multirow{3}{*}{26,3} & \multirow{3}{*}{1,2} \\
\hline 07 & & 4,1 & & & 27 & & \\
\hline 08 & & 4,0 & & & 27 & & \\
\hline 09 & \multirow{3}{*}{7} & 6,8 & \multirow{3}{*}{6,9} & \multirow{3}{*}{0,1} & 30 & \multirow{3}{*}{29,3} & \multirow{3}{*}{0,6} \\
\hline 10 & & 7,0 & & & 29 & & \\
\hline 11 & & 6,9 & & & 29 & & \\
\hline 12 & \multirow{3}{*}{9} & 8,7 & \multirow{3}{*}{8,8} & \multirow{3}{*}{0,1} & 20 & \multirow{3}{*}{20,0} & \multirow{3}{*}{2,0} \\
\hline 13 & & 8,9 & & & 18 & & \\
\hline 14 & & 8,9 & & & 22 & & \\
\hline
\end{tabular}

Fonte: Autores

Tabela 4 - Dados de crescimento, pH e esterilidade após a Biotransformação

\begin{tabular}{|c|c|c|c|c|c|c|c|}
\hline \multirow{2}{*}{ Frasco } & \multirow{2}{*}{$\begin{array}{c}\text { Esterilidade antes da } \\
\text { biotransformação }\end{array}$} & \multicolumn{5}{|c|}{ Após a biotransformação } \\
\cline { 3 - 8 } & Positivo & Individual & Média & Erro & Individual & Média & Erro \\
\hline 01 e 02 & Positivo & - & - & - & - & - & - \\
\hline 03 & Positivo & 6,2 & 6,1 & 0,1 & 25 & 25,3 & 0,6 \\
\hline 04 & Positivo & 6,1 & & & 25 & & \\
\hline 05 & Positivo & 6,1 & & & 26 & & \\
\hline 06 & Positivo & 3,9 & 4,0 & 0,1 & 20 & 21,0 & 1,0 \\
\hline 07 & Positivo & 3,1 & & & 21 & & \\
\hline 08 & Positivo & 6,8 & 6,9 & 0,1 & 27 & 26,3 & 1,2 \\
\hline 09 & Positivo & 6,9 & & & 27 & & \\
\hline 10 & Positivo & 6,9 & & & 25 & & \\
\hline 11 & Positivo & 8,8 & 8,8 & 0,1 & 17 & 17,3 & 0,6 \\
\hline 12 & Positivo & 8,8 & & & 17 & & \\
\hline 13 & Positivo & 8,9 & & & 18 & & \\
\hline 14 & & & & & 22 & & \\
\hline
\end{tabular}

Fonte: Autores 
O gráfico 1 demonstra que sem controle de $\mathrm{pH}$ através de tamponamento do meio, a variação do $\mathrm{pH}$ após a biotransformação é maior do que nos meios tamponados.

Gráfico 1 - Comparação de pH antes e após a biotransformação.

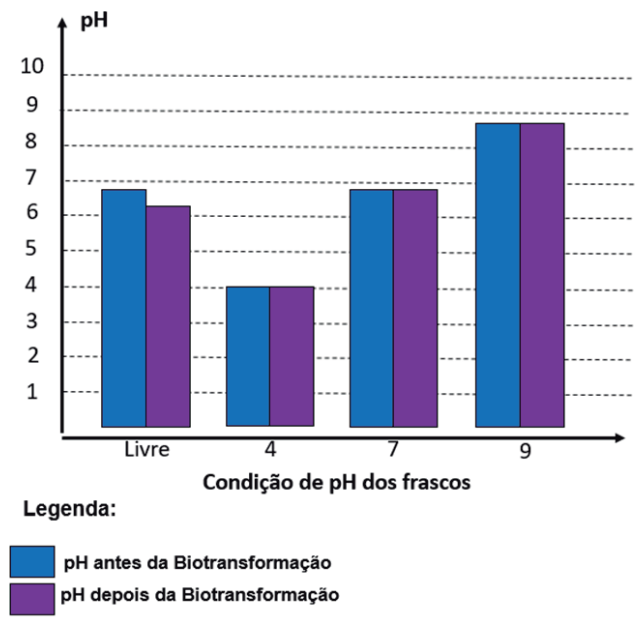

Fonte: Autores

Pode-se visualizar no gráfico 2 que a menor variação de crescimento encontrada entre as amostras antes e após a biotransformação ocorreu nos frascos com controle de $\mathrm{pH}$ em 7,0. Cabe destacar que em todos os casos a diminuição do crescimento deve-se à curva de crescimento microbiano, onde o microorganismo já começa a entrar na fase de declínio ou desaceleração. Nas outras condições de pH livre, 4,0 e 9,0 a diminuição do crescimento foi mais intensa e isso provavelmente foi acentuado devido a um desvio do $\mathrm{pH}$ ótimo de crescimento do microorganismo.

Gráfico 2 - Comparação de crescimento antes e após a biotransformação.

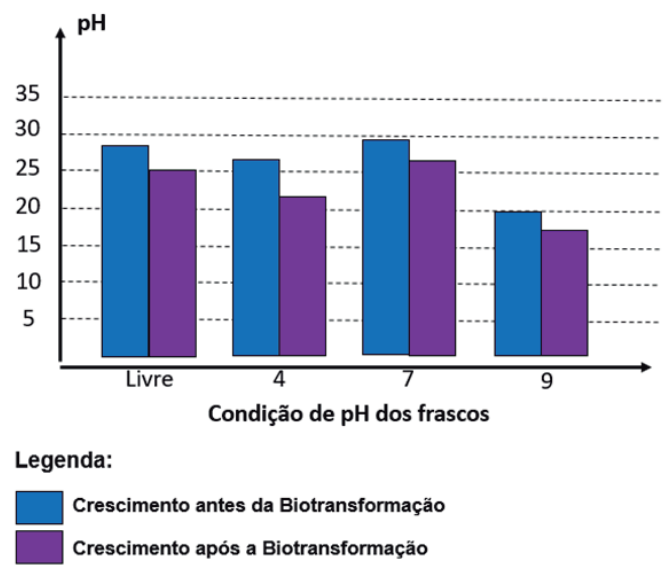

Fonte: Autores
No gráfico 3 observamos que a melhor condição de biotransformação é a dos frascos com pH controlado em 7,0, onde todo o esteroide de partida foi consumindo e a condição menos favorável foi a de $\mathrm{pH}$ controlado em 9,0 onde menos de $20 \%$ do esteroide de partida foi transformado.

Gráfico 3 - Rendimento da biotransformação.

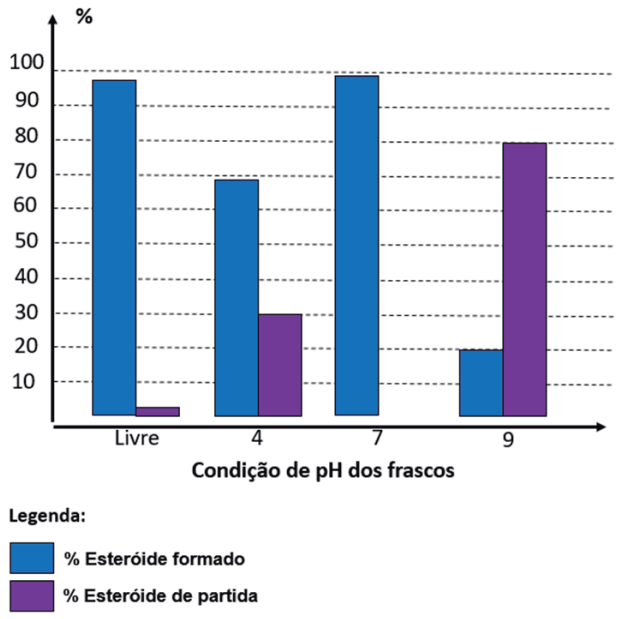

Fonte: Autores

\section{Discussão}

Os resultados apresentados no gráfico 3 evidenciaram claramente que com o controle de $\mathrm{pH}$ em 7,0 a transformação é completa não restando nenhum esteroide de partida. Como mencionado anteriormente, o controle de $\mathrm{pH}$ faz com que tenhamos uma porcentagem de transformação mais eficiente do que os resultados obtidos sem controle de pH (tabela 3 ). Em contrapartida demonstrou-se também que mesmo com o controle de $\mathrm{pH}$, existe uma faixa ótima de trabalho para que a transformação ocorra. O gráfico 3 evidências de que em $\mathrm{pH}$ fora dessa faixa a transformação não é completa. Em pH muito baixo ou muito alto o sistema enzimático fica prejudicado não tendo eficácia na biotransformação conforme os dados apresentados na tabela 3 .

Segundo estudos realizados por Sukhodol e colaboradores (1984) ficou evidenciado que a biotransformação de esteroides pelo fungo Curvularia lunata não sofre alteração para variações de $\mathrm{pH}$ de 4,0 a 6,0. Hanc e colaboradores (1961) observaram que a biotransformação de esteroides pela cultura de Absidia orchidis tanto em condições ácidas ( $\mathrm{pH} 4,0$ a 5,0) quanto em condições alcalinas ( $\mathrm{pH} 7,5$ a 8,0) é 
inibida. A tabela 5 mostra os resultados obtidos neste experimento, a faixa de $\mathrm{pH}$ utilizada foi mais estreita que a utilizada no nosso caso, mas pode-se muito bem ver que o pH ótimo para a transformação no caso de Hanc e colaboradores (1961) foi de 6,5.

Tabela 5 - O efeito do pH no curso da transformação de esteroide S (HANC et. al., 1961)

\begin{tabular}{|c|c|c|c|c|c|c|}
\hline \multirow{2}{*}{$\mathbf{p H}$} & \multicolumn{4}{|c|}{ Incubação em horas } \\
\cline { 2 - 7 } & \multicolumn{2}{|c|}{$\mathbf{1 5}$} & \multicolumn{2}{c|}{$\mathbf{2 0}$} & \multicolumn{2}{c|}{$\mathbf{2 4}$} \\
\cline { 2 - 7 } & Cortisol \% & Epicortisol \% & Cortisol \% & Epicortisol \% & Cortisol \% & Epicortisol \% \\
\hline 4,4 & 18,6 & 17,2 & 20,0 & 19,8 & 23,8 & 22,4 \\
\hline 5,5 & 44,1 & 42,8 & 46,2 & 44,6 & 46,0 & 44,3 \\
\hline 6,5 & 49,7 & 44,1 & 48,9 & 43,9 & 48,9 & 43,6 \\
\hline 7,3 & 43,8 & 40,9 & 44,6 & 42,8 & 45,8 & 43,0 \\
\hline 8,0 & 27,1 & 25,4 & 30,9 & 26,1 & 33,5 & 28,2 \\
\hline
\end{tabular}

Hanc e colaboradores (1961) ainda verificaram que o metanol foi o solvente mais aceitável para a extração do esteroide do meio de cultura em comparação aos solventes etanol e acetona. Para o estudo deste experimento utilizamos o metanol nas extrações do esteroide.

\section{Conclusão}

Através das literaturas levantadas e testes realizados no laboratório para este estudo, é possível afirmar que o experimento evidenciou que o sistema enzimático pode ou não ser afetado pela alteração de $\mathrm{pH}$, isso vai depender de qual é o microrganismo gerador das enzimas.

$\mathrm{O}$ uso de tampões no meio para o controle de $\mathrm{pH}$ garante que a enzima transforme todo o esteroide de partida, tendo, portanto, a melhor relação de transformação.

O melhor para conduzir o processo de biotransformação em Rhizopus arrhizus fazendo com que tenhamos o maior rendimento, foi para $\mathrm{pH}$ igual a 7,0 . Cabe destacar que industrialmente o custo do tamponamento do meio para $\mathrm{pH} \mathrm{7,0}$ pode ser, maior que o ganho em rendimento quando comparado com a condição de $\mathrm{pH}$ livre, podendo ser, mais rentável a biotransformação em $\mathrm{pH}$ livre. Para utilização em escala industrial, cabe um estudo de viabilidade econômica e também elaboração de uma análise de risco, levando em consideração que o controle do $\mathrm{pH}$, sendo que para o controle em escala industrial será necessário a implementação de tanques adicionais para o ajuste durante o processo fermentativo (crescimento e biotransformação), aumentando os risco de contaminação por intermédio deste tanques adicionais. Podendo estes ajustes serem realizados com soluções estéreis de base e ou ácidas. Pode ser observado também que após a transformação com a pH controlado em 7 o crescimento mantivesse maior em relação aos outros experimentos.

Nas outras duas faixas de $\mathrm{pH}$ devem ocorrer uma alteração na conformação tridimensional da enzima, fazendo com que não tenhamos um resultado satisfatório na biotransformação.

\section{Referências}

AQUARONE E., BORZANI W. \& LIMA U.A. Biotecnologia - Tópicos de Microbiologia Industrial volume 2. $1^{\text {a }}$ edição. São Paulo: Ed. Edgard Blücher Ltda., 1975.

AQUARONE E., BORZANI W. \& LIMA U.A. Biotecnologia - Engenharia Bioquímica - volume 3. $1^{\text {a }}$ edição. São Paulo: Ed. Edgard Blücher Ltda., 1975.

BASTOS, REINALDO GASPAR. Tenológia das fermentações: fundamentos de bioprocessos / Reinaldo Gaspar Bastos. - São Carlos: EdUFSCar, 2010.

CASTRO, H. F., MENDES, A. A., SANTOS, J.C., AGUIAR, C. L., 2004, Modificações de óleos e gorduras por biotransformação, química nova, volume 27, pág. 146-156.

FABER K. Biotransformations in Organic Chemistry A textbook. $3^{a}$ edição. Alemanha: Ed. Springer, 1997.

GUYTON A. C. \& HALL J.E. Fisiologia Humana e Mecanismos de Doenças. $6^{a}$ edição. Rio de Janeiro: 
Ed. Guanabara Koogan, 1998.

G. V. SUKHODOL'SKAYA, B. A. ANGELOVA and K. A. KOSCHEENKO, "Physiological and Biochemical Properties of a Culture of Curvularia lunata VKM F-644 with the Ability to Achieve 11 $\beta$-Hidroxilation of Steroid Substrates.

HANCE, O., CAPEK, A., KAKAC, B.: Transformation of steroid $\mathrm{S}$ (Reichstein) by Absidia orchidis. Folia microbio. 6:392, 1961.

LIMA U.A., AQUARONE E., BORZANI W. \& SCHMIDELL W. Biotecnologia Industrial - Processos Fermentativos e Enzimáticos - volume 3. $1^{\text {a }}$ edição. São Paulo: Ed. Edgard Blücher Ltda., 2001.

MARZZOCO A. \& TORRES B.B. Bioquímica Básica. $2^{a}$ edição. Rio de Janeiro: Ed. Guanabara Koogan, 1999.

MORRISON R. T. \& BOYD R. N. Química Orgânica. 13a edição. Delaware: Ed. Addison-Wesley Iberoamericana, 1997.

MAJORS, R. E.; LC-GC Special Issue on Current Issues in HPLC Technology, May 1997, S8

O. HANC, A. CAPEK, and B. KAKAC, "Microbiological transformation of steroids. XV. Transformation of steroid S (Reichstein) by Absidia orchidis 310, Folia Microbiol., 6, No 6, 392-397 (1961).

SHELDON R. A. Chirotechnology - Industrial synthesis of optically active compounds. $1^{\text {a }}$ edição. New York: Ed. Marcel Dekker Inc.

RAVEN P.H, EVERT R.F. \& EICHHORN S.E. Biologia Vegetal. $6^{a}$ edição. Rio de Janeiro: Ed. Guanabara - Koogan, 2001. 906p.

RODRIGUES, P. H. M., ALMEIDA, L. F. S., LUCCI, C. S., MELLOTI, L., LIMA, F. R., 2004, Efeitos da adição de inoculantes microbianos sobre o perfil fermentativo da silagem de alfafa adicionada de polpa cítrica, revista brasileira de Zootecnia, volume 33, pág. 1643-1653.

TRABULSI L. R. \& TOLEDO M. R. F. Microbiologia. $2^{\text {a }}$ edição. Rio de Janeiro: Ed. Atheneu, 1989.

VOLPE, P. L. O., 1997, Estudo da fermentação alcoólica de soluções diluídas de diferentes açucares utilizando microcalorimetria de fluxo, Química nova, pág 20-25. 